\title{
The optimized strategy of urban rail transit project under Public-Private-Partnerships in China: Based on the maximum government benefit
}

\author{
Fei-ran Liu, a , Jun Liu' ${ }^{2, b}$ and Xue-dong Yanº \\ 1,2,3 School of Traffic and Transportation, Beijing Jiaotong University, Beijing 100044, China; \\ a feiranliu@126.com, bjliu@bjtu.edu.cn, cxdyan@bjtu.edu.cn
}

Keywords: Engineering Economics; Decision Analysis; Nonlinear Programing; Urban Rail Transit; Public-Private-Partnerships; Value for Money.

\begin{abstract}
As the Public-Private-Partnership (PPP) in the domain of urban rail goes further, government policy makers care more about if any acceptable decision exists in project and maximum extent of Value for Money (VFM). However, the existing decision-making evaluation method may provide invalid and inaccurate results of the two questions. This paper proposes an optimized method which establishes a nonlinear programming model to find the decision that satisfies the private sector with reasonable payback while maximizing VFM and takes the maximum VFM value as a judge. According results of multiple independently repeated trials, the optimized method could provide valid evaluation results of the two questions under 5 scenarios of PPP project decision with the least one-time accurate rate above $76 \%$. Thus, method pro-posed in this paper could be used as an auxiliary tool for urban rail transit project PPP decision making.
\end{abstract}

\section{Introduction}

Rapid development of Urban Rail Transit (URT) in China has generated huge capital demand in decades. In order to solve the funds shortage problem in traditional financing mode that rely on only government debt, the Public-Private Partnerships (PPP) is introduced into field of URT as one new financing mode [1]. There is no common definition of PPP recognized world-widely at present stage. According to the government document published by Ministry of Finance of the People's Republic of China in 2014, the PPP model is a kind of partnership be-tween the public sector and private sector to establish a long-term cooperative relation to provide infrastructure and public service or product, that the most of responsibilities in design, construction, operation and maintenance of the infra-structure project are borne by the private sector, who could get returns through user payment and government subsidy [2]. Present administrative policy applied in PPP practice requires project under PPP mode (short for PPP project) should be passed the Value For Money (VFM) evaluation, in which the life-cycle project cost government spent on could not be more than that spent in traditional financing mode [3]. The difference between the PSC value and life-cycle cost of PPP project in its present value is the VFM value [4]. From above it could be seen that a financial feasibly decision of a PPP project should be accepted by both the public sector and the private sector that VFM value from the former should not be negative, and the expected returns should be received by the later.

Whether one strategy of a PPP project in decision-making is acceptable or not depends on the evaluation criteria, which is also the focus of scholars. Zhang X R [5] defined the composition PSC value, PPP value and the private sector's return of urban rail transit project based on the quantitative evaluation framework of VFM in China, as well provided the method to calculate them. Tang L [6], taking non-operating highway project as an example, proposed that the discount rate risk considered for calculating VFM value and reasonable returns of the private sector could be determined by the Capital Asset Pricing Model (CAPM). Luo Y Y [7] quantified the impact of project risk by Analytic Hierarchy Process (AHP) approach and the Set-valued Statistics method then provided the risk cost allocation model under PPP mode. Zhao Y D [8] proposed the method for calculating VFM value, 
PPP value and the private sector's return through the PSC value and the preset rate of VFM value, starting from perspective of present value of project life-cycle cost and revenue.

These existing studies for urban rail transit PPP project in China provided some effective solutions in URT PPP project decision-making as guidance. However, policymakers from the public sector pay more attention to the following two is-sues: first, whether there is existing an acceptable strategy for the project (non-negative value of VFM and returns of the private sector); second, how much is the maximum value of VFM upon that acceptable strategy. Existing method in practice is to choose a series strategy to try them each by each individually (Figure 1). However, this approach is apparently difficult to solve the two issues simultaneously and accurately. This paper proposes an improved decision-making evaluation method to optimize the strategy of URT PPP project: establish a non-linear programing model with the maximum present value of VFM as objective and non-negative present value of expected payback of the private sector as main constrain to get the solution that satisfied the two issues both. Interpretation of this optimization model result is shown in Figure 2: If the corresponding VFM value calculated on the strategy solved by the optimization model, there is no acceptable decision for the project, which means that the answer for the first is-sue is 'no'; else, the present value of VFM is non-negative, means the answer for the first issue is 'yes', also the value of objective is the answer of the second issue. Effectiveness of the optimized model are verified via 10000 independent repeated trials based on a sample case.

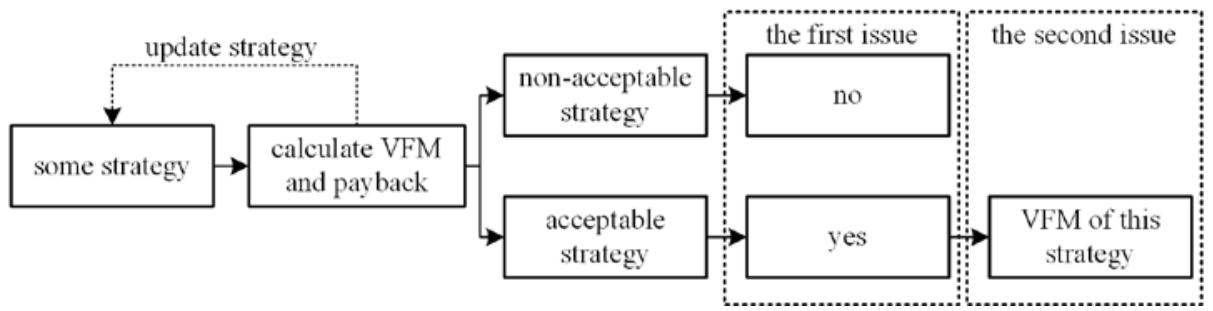

Fig. 1. Process of existing decision-making evaluation of PPP project

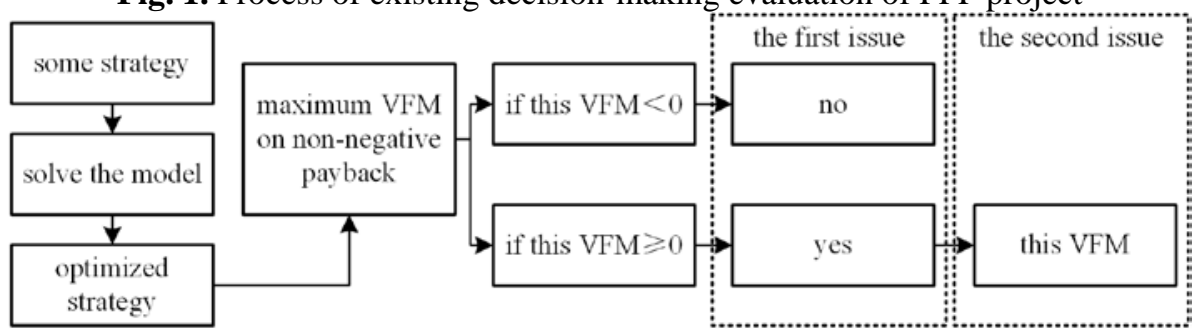

Fig. 1. Process of the optimization model for decision-making evaluation of PPP project proposed in this paper

\section{Modelling}

Parameter Selection. Parameters for calculation of VFM and the private sector's payback [9] could be generated from feasible research report of URT PPP project which are listed in Table 1. 
Table 1. Parameters and interpretation used in the optimized model

\begin{tabular}{|c|c|}
\hline Parameter & Interpretation \\
\hline$I_{c}$ & Construction cost $\left(\right.$ Yuan $\left.\times 10^{4}\right)$ \\
\hline$N$ & Construction period (year) \\
\hline$\gamma$ & Cooperation period(overlapped with operation period in PPP, year) \\
\hline$M_{\mathrm{v}}$ & Planned operating kilometers each year $\left(\mathrm{km} × 10^{4} /\right.$ vehicle/year) \\
\hline$E$ & Operation cost each year (YUAN/km/vehicle/year) \\
\hline$Q_{0}$ & $\begin{array}{l}\text { Passenger turnover volume of the } 1 \text {-st year of operation } \\
\left(10^{4} \times \mathrm{km} \times \text { passenger/year }\right)\end{array}$ \\
\hline$\delta$ & Ticket fare (Yuan/passenger/km) \\
\hline$R_{q}$ & Annual growth rate of passenger turnover volume (\%) \\
\hline$R_{n t}$ & $\begin{array}{l}\text { Percentage of non-ticket revenue (retailing, communication service, } \\
\text { advertisement) take up ticket revenue (\%) }\end{array}$ \\
\hline$\alpha$ & Equity ratio of the public sector under PPP mode (\%) \\
\hline$\beta$ & $\begin{array}{l}\text { Unit subsidy under PPP mode from the public sector } \\
\text { (Yuan/vehicle/km) }\end{array}$ \\
\hline$R_{g}$ & Discount rate of the public sector (\%) \\
\hline$R_{p}$ & $\begin{array}{l}\text { Expected rate of returns, used as discount rate for the private sector } \\
\text { (\%) }\end{array}$ \\
\hline$R_{d e v}$ & $\begin{array}{l}\text { Ratio of commercial development benefit obtained by the private } \\
\text { sector under PPP mode on total construction investment (\%) }\end{array}$ \\
\hline$R_{r c}$ & Factor of risk related to cost during construction stage \\
\hline$R_{r t}$ & Factor of risk related to revenue during operation stage \\
\hline$R_{\text {re }}$ & Factor of risk related to cost during operation stage \\
\hline$R_{\text {rep }}$ & Ratio of operation cost spent by the private sector (\%) \\
\hline$R_{\operatorname{tax}}$ & Combined tax rate of project (\%) \\
\hline$M_{\text {avg }}$ & Average travelling distance per passenger per trip (km/passenger) \\
\hline$E_{\text {avg }}$ & Average cost per passenger per trip (Yuan/passenger) \\
\hline$S$ & General public budget at the year operation starts (Yuan $\times 10^{4}$ ) \\
\hline$Y$ & Present value of VFM $\left(\right.$ Yuan $\left.\times 10^{4}\right)$ \\
\hline$U$ & Present value of the private sector's payback $\left(\right.$ Yuan $\left.\times 10^{4}\right)$ \\
\hline
\end{tabular}

In Table $1, \alpha, \beta, \delta$ and $\gamma$ are the strategy variables whose value determined by the decision-makers from the public sector and noted as $x_{1}, x_{2}, x_{3}$ and $x_{4}$. The others whose value are not determined or affected by the public sector are treated as constant parameters, includes $I_{c}, N, M_{v}, E$, $Q_{0}, R_{q}, R_{n t}$ determined by the technical and economic characteristics of the project; $R_{g}, R_{r c}, R_{r e}, R_{r t}$ determined in group-decision of specialists of URT industry; $R_{p}$ and $R_{\text {rep }}$, determined by decision-makers from the private sector; $M_{\text {avg }}$ and $E_{\text {avg }}$, derived from URT statistic data of the city where project constructed; $s$, usually found in the public government document released by finance administrative department of the city. $Y$ and $U$ are calculated on these parameters. Non-negative value of $Z$ manifests the private sector get expected payback.

$\overline{x_{1}}, \overline{x_{2}}, \overline{x_{3}}, \overline{x_{4}}$ are used to represent the upper of value range of strategy variables and $\underline{x_{1}}, \underline{x_{2}}, \underline{x_{3}}, \underline{x_{4}}$ are used as the bottom. The public sector cannot be the controlling shareholder is require by existing administrative order from Ministry of Finance of the People's Republic of China. The limit of equity ratio usually is $49 \%$ in practice, so $\overline{x_{1}}=49 \%$. Number of URT PPP projects planned to deliver in a domestic city is usually not more than one in a year, thus

$$
\overline{x_{2}}=S / M_{\text {avg }}
$$

Considering the public-welfare attribute of URT project, the maximum ticket fare should be limited at the level just covers project construction and operation cost, thus

$$
\overline{X_{3}}=E_{\text {avg }} / M_{\text {avg }}
$$


Considering the concession period is up to 30 years and URT project practical operation period is not less than 15 years in China, $\overline{x 4}=30, \underline{x 4}=15$.

Build the Non-linear Programing Model. The optimization model takes maximization of $Y$ as the objective and $U \geq 0$ as the main constrain. $Y$ and $U$ are calculated by

$$
\begin{aligned}
Y= & \left(1+R_{r c}\right) \cdot\left(1-x_{1}\right) \cdot I_{c}+\left(E \cdot\left(1+R_{r c} \cdot R_{r e p}\right)-x_{2}\right) \cdot M_{v} \cdot \frac{\left(1+R_{g}\right)^{x_{4}}-1}{\left(1+R_{g}\right)^{x_{4}+N} \cdot R_{g}}- \\
& \left(1-R_{r t}\right) \cdot\left(1+R_{n t}\right) \cdot x_{3} \cdot Q_{0} \cdot \frac{\left(1+R_{q}\right)^{x_{4}}-\left(1+R_{g}\right)^{x_{4}}}{\left(1+R_{q}\right)^{x_{4}} \cdot\left(R_{q}-R_{g}\right) \cdot\left(1+R_{g}\right)^{N-1}}+Z \cdot R_{t a x} \\
U= & \left(x_{2}-E \cdot\left(1+R_{r e} \cdot R_{r e p}\right)\right) \cdot M_{v} \cdot \frac{\left(1+R_{p}\right)^{x_{4}}-1}{\left(1+R_{p}\right)^{x_{4}+N} \cdot R_{p}}+\left(R_{d e v}-\left(1+R_{r c}\right) \cdot\left(1-x_{1}\right)\right) \cdot I_{c}+ \\
& \left(1-R_{r t}\right) \cdot\left(1+R_{n t}\right) \cdot x_{3} \cdot Q_{0} \cdot \frac{\left(1+R_{q}\right)^{x_{4}}-\left(1+R_{p}\right)^{x_{4}}}{\left(1+R_{q}\right)^{x_{4}} \cdot\left(R_{q}-R_{p}\right) \cdot\left(1+R_{p}\right)^{N-1}}
\end{aligned}
$$

According to equation (1)-(4), the non-linear programing model is expressed as $\max z=Y$

s.t.

$$
U \geq 0 ; 0 \leq x_{1} \leq 0.49 ; 0 \leq x_{2} \leq S / M_{\text {avg }} ; 0 \leq x_{3} \leq E_{\text {avg }} / M_{\text {avg }} ; 15 \leq x_{4} \leq 30 \text {. }
$$

\section{Independently Repeated Trials}

In order to simulate the actual decision-making situation, 10,000 independently repeated trials are carried out in each of 5 scenario in practice to verify the effectiveness of the optimization model. $x_{1}$, $x_{2}, x_{3}, x_{4}$ separately takes a random number within its range to form a random strategy at beginning of each trial. The precision of these random numbers are $0.01,0.01,0.01$ and 1 . This random strategy is evaluated by both the existing decision method and the optimized model, and values of $Y$ and $U$ are record.

Procedure Parameters. They are listed as follow:

$i$ : Current trial order.

$i_{\max }$ : Maximum times of trial, 10000.

$A[]: i_{\max } \times 12$ matrix variable used to store results.

$X_{1 i}^{\prime}, X_{2 i}^{\prime}, X_{3 i}^{\prime}, X_{4 i}^{\prime}$ : Random values generated by strategy variable $x_{1}, x_{2}, x_{3}, x_{4}$ in the i-th trial.

$X_{1 i}^{*}, \quad X_{2 i}^{*}, \quad X_{3 i}^{*}, X_{4 i}^{*}$ : Non-interior solution of the optimization model in the i-th trial.

$Y_{i}^{\prime}, \quad U_{i}^{\prime}$ : Present values of VFM and payback calculated by substituting $X_{1 i}^{\prime}, X_{2 i}^{\prime}, X_{3 i}^{\prime}, X_{4 i}^{\prime}$ in equation

(3) and (4) via the existing evaluation method.

$Y_{i}^{*}, U_{i}^{*}$ : Present values of VFM and payback calculated by substituting $X_{1 i}^{*}, X_{2 i}^{*}, X_{3 i}^{*}, X_{4 i}^{*}$ in equation

(3) and (4).

$q^{\prime}$ : Number of acceptable strategies generated by the existing method.

$q^{*}$ : Number of acceptable strategies generated by the optimization model.

Process of Independent Trial. For each one scenario in practice, the following steps are shown in Figure 3.

STEP 1: Start.

STEP 2: Obtain constant parameters from project files.

STEP 3: Initialize $i=1, q^{\prime}=0, q^{*}=0, A[]=0$.

STEP 4: Determine whether the maximum times of trials has been reached. If $i \leq i_{\max }$, go to the next step, else go to STEP 10.

STEP 5: Each of $x_{1}, x_{2}, x_{3}, x_{4}$ generates the random number $X_{1 i}^{\prime}, X_{2 i}^{\prime}, X_{3 i}^{\prime}, X_{4 i}^{\prime}$ within its value range. 
STEP 6: Substitute $X_{1 i}^{\prime}, X_{2 i}^{\prime}, X_{3 i}^{\prime}, X_{4 i}^{\prime}$ into equation (3) and (4) to get $Y_{i}^{\prime}$ and $U_{i}^{\prime}$; Meantime, take $X_{1 i}^{\prime}, X_{2 i}^{\prime}$, $X_{3 i}^{\prime}, X_{4 i}^{\prime}$ as initial input of the optimization model to get $X_{1 i}^{*}, X_{2 i}^{*}, X_{3 i}^{*}, X_{4 i}^{*}$, which are then substituted into equation (3) and (4) to get $Y_{i}^{*}$ and $U_{i}^{*}$.

STEP 7: Classify the calculation results and update the number of acceptable strategies. If $Y_{i}^{\prime} \geq 0$ and $U_{i}^{\prime} \geq 0$, then $q^{\prime}=q^{\prime}+1$; If $Y_{i}^{*} \geq 0$ and $U_{i}^{*} \geq 0$, then $q^{*}=q^{*}+1$.

STEP 8: Change the i-th row vector of $A[]$ as $\left[Y_{i}^{\prime}, U_{i}^{\prime}, Y_{i}^{*}, U_{i}^{*}, X_{1 i}^{\prime}, X_{2 i}^{\prime}, X_{3 i}^{\prime}, X_{4 i}^{\prime}, X_{1 i}^{*}, X_{2 i}^{*}, X_{3 i}^{*}, X_{4 i}^{*}\right]$.

STEP 9: Update $i=i+1$, then go back to STEP 2.

STEP 10: Write $A[$ ] into file.

STEP 11: End.

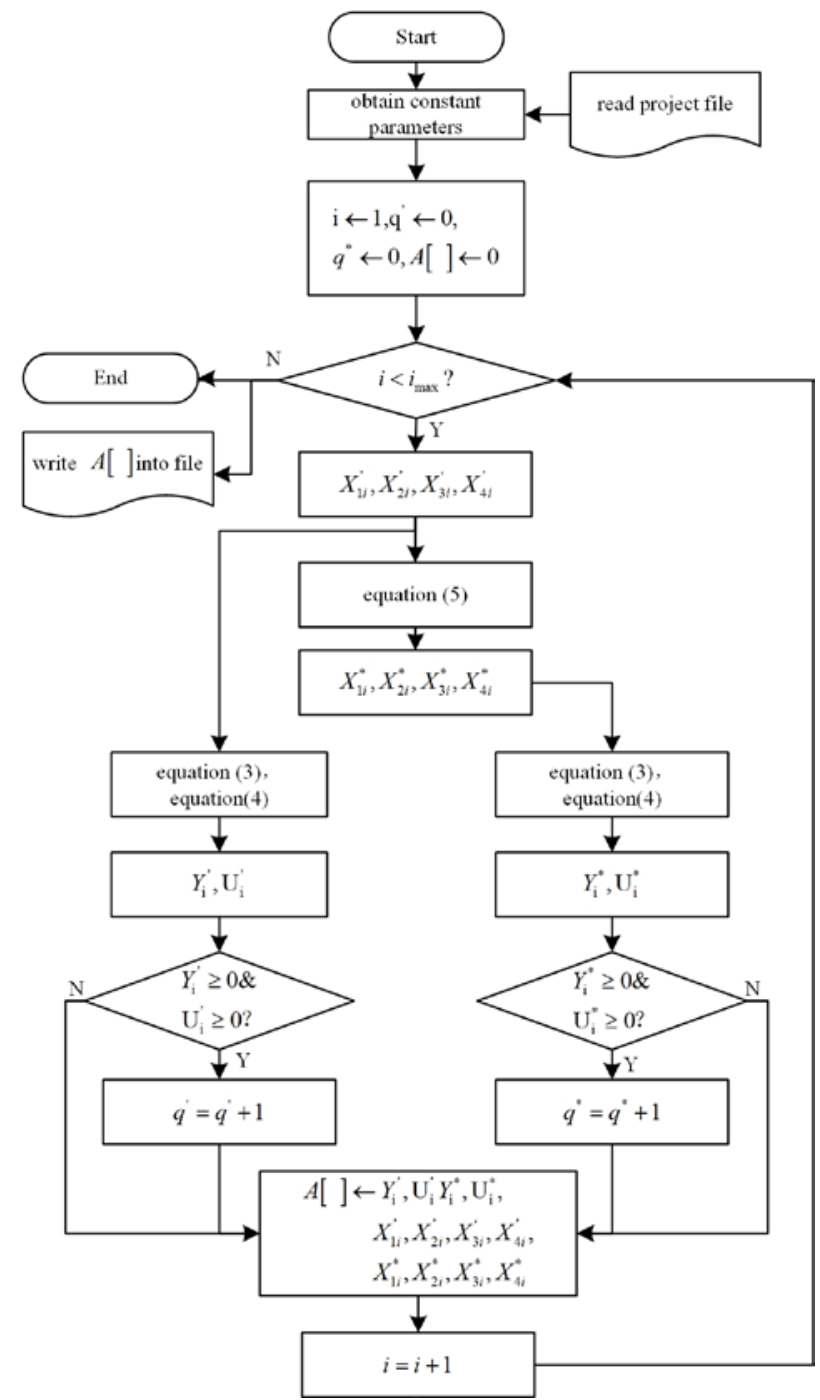

Fig. 2. Flow chart of independent trial

\section{Case Study}

There is a big west-south city in China plans to deliver a URT project under PPP mode. This project is constructed as the first phase of line 17, and its construction period starts from January 2017 and ends at December 2012. A project company is established on jointly funding by the public sector and the private sector. Investment of the project (total construction cost) is divided by equity ratio of both parties. The residual asset value of the project at the end of operation period is 0 . Base year of present value is 2017. Table 2 gives the value of parameters listed in Table 1. 
Table 2. Constants parameter values in the case project

\begin{tabular}{lrr}
\hline Parameter & Value & Unit \\
\hline$I_{c}$ & 1588306 & Yuan $\times 10^{4}$ \\
$N$ & 4 & year \\
$M_{\mathrm{v}}$ & 2667 & $\mathrm{~km} \times 10^{4} /$ vehicle/year \\
$E$ & 16.22 & Yuan $/ \mathrm{km} /$ vehicle/year \\
$Q_{0}$ & 36318 & $10^{4} \times \mathrm{km} \times$ passenger/year \\
$R_{q}$ & 5 & $\%$ \\
$R_{n t}$ & 8 & $\%$ \\
$R_{g}$ & 4.9 & $\%$ \\
$R_{p}$ & 6 & $\%$ \\
$R_{r c}$ & 0.05 & - \\
$R_{r t}$ & 0.1 & - \\
$R_{r e}$ & 0.1 & - \\
$R_{\text {rep }}$ & 90 & $\%$ \\
$R_{\text {tax }}$ & 25 & km/passenger \\
$M_{\text {avg }}$ & 15 & Yuan/passenger \\
$E_{\text {avg }}$ & 8.56 & Yuan $\times 10^{4}$ \\
$S$ & 191180 & \\
\hline
\end{tabular}

There could be 5 different scenarios in practice:

Scenario A: The private sector obtained commercial development benefit that takes up $10 \%$ of project investment, $R_{d e v}=10 \%$.

Scenario B: There is no commercial development benefit, $R_{d e v}=0$.

Scenario C: There is no commercial development benefit; Equity ratio of the public sector is fixed as the minimum capital ratio (20\%) that required by administrative order, $R_{\text {dev }}=0, \quad x_{1} \equiv 0.2$.

Scenario D: There is no commercial development benefit; Ticket fare are fixed as the recommended level in project feasible report, $R_{\text {dev }}=0, \quad x_{3} \equiv 0.33$.

Scenario E: There is no commercial development benefit; Cooperation period is fixed as the average length of URT project operation period in China, 26.6 years, calculated on the data of URT PPP projects in purchasing phase and later phase archived by China Public-Private-Partnerships Center (CPPPC) [10], $R_{\text {dev }}=0, x_{4} \equiv 26.6$.

\section{Results and Discussion}

Table 3. Results of trails of existing evaluation method

\begin{tabular}{cccccc}
\hline scenarios & $\begin{array}{c}\text { number of } \\
\text { acceptable } \\
\text { strategies }\end{array}$ & $Y_{\max }^{\prime} \times 10^{4}$ & $U^{\prime} \times 10^{4}$ & $\begin{array}{c}\text { any } \\
\text { acceptable } \\
\text { strategy }\end{array}$ & $\begin{array}{c}Y_{\max } \times 10^{4} \text { in } \\
\text { acceptable } \\
\text { strategies }\end{array}$ \\
\hline A & 262 & 13.37 & 0.71 & yes & 13.37 \\
B & 0 & -2.71 & 1.02 & no & - \\
C & 0 & -9.66 & 0.25 & no & - \\
D & 0 & -6.92 & 0.74 & no & - \\
E & 0 & -3.74 & 0.74 & no & - \\
\hline
\end{tabular}

Table 3 shows the results of 10,000 independently repeated trials generated by existing evaluation method under 5 different scenarios. $Y_{\max }^{\prime}$ is the maximum VFM value when $U \geq 0$ (the private sector got expected payback). $U^{\prime}$ is the present value of payback when $Y$ achieved $Y_{\max }^{\prime}$. There are 263 acceptable strategies under scenario A, among them $Y_{\max }^{\prime}$ is $13.37 \times 10^{4}$. There is no any acceptable strategy under scenario B, C, D and E. Thus, for the 1-st issue mentioned in Introduction part, result of existing evaluation method shows that there are acceptable strategies under scenario A but no acceptable strategy under scenario B, C, D and E; for the 2-nd issue, result of ex result of existing evaluation method shows the maximum VFM value $\left(Y_{\max } \times 10^{4}\right)$ is 13.37 relied on experience from practice. 
Table 4. results of trails of optimized evaluation method

\begin{tabular}{|c|c|c|c|c|c|}
\hline \multirow[b]{2}{*}{ scenarios } & \multirow{2}{*}{$\begin{array}{l}\text { number of } \\
\text { acceptable } \\
\text { strategies }\end{array}$} & \multicolumn{2}{|c|}{ when $U \geq 0$} & \multirow{2}{*}{$\begin{array}{c}\text { any } \\
\text { acceptable } \\
\text { strategy }\end{array}$} & \multirow{2}{*}{$\begin{array}{l}Y_{\max } \times 10^{4} \text { in } \\
\text { acceptable } \\
\text { strategies }\end{array}$} \\
\hline & & $Y_{\max }^{*} \times 10^{4}$ & $U^{*} \times 10^{4}$ & & \\
\hline $\mathrm{A}$ & 9924 & 19.91 & 0 & yes & 19.91 \\
\hline B & 8426 & 1.2 & 0 & yes & 1.2 \\
\hline $\mathrm{C}$ & 0 & -7.39 & 0 & no & - \\
\hline $\mathrm{D}$ & 0 & -5.67 & 0 & no & - \\
\hline $\mathrm{E}$ & 0 & -1.28 & 0 & no & - \\
\hline E & 0 & -3.74 & 0.74 & no & - \\
\hline
\end{tabular}

Table 4 shows the results of 10,000 independently repeated trials generated by the optimization model under 5 different scenarios. $Y_{\max }^{*}$ is the maximum value of VFM when the private sector got expected payback $(U \geq 0)$.There are acceptable strategies exist in scenario A and B. Number of them is separately 9924,8426 and $Y_{\max }^{*} \times 10^{4}$ is $19.91,1.2$. For the 1 -st issue in Introduction, the optimization model gave the result that there are acceptable strategies under scenario $\mathrm{A}, \mathrm{B}$ and none of that under scenario C, D, E; For the 2-nd issue, maximum value of VFM is 19.91 under scenario A and 1.2 under scenario B.

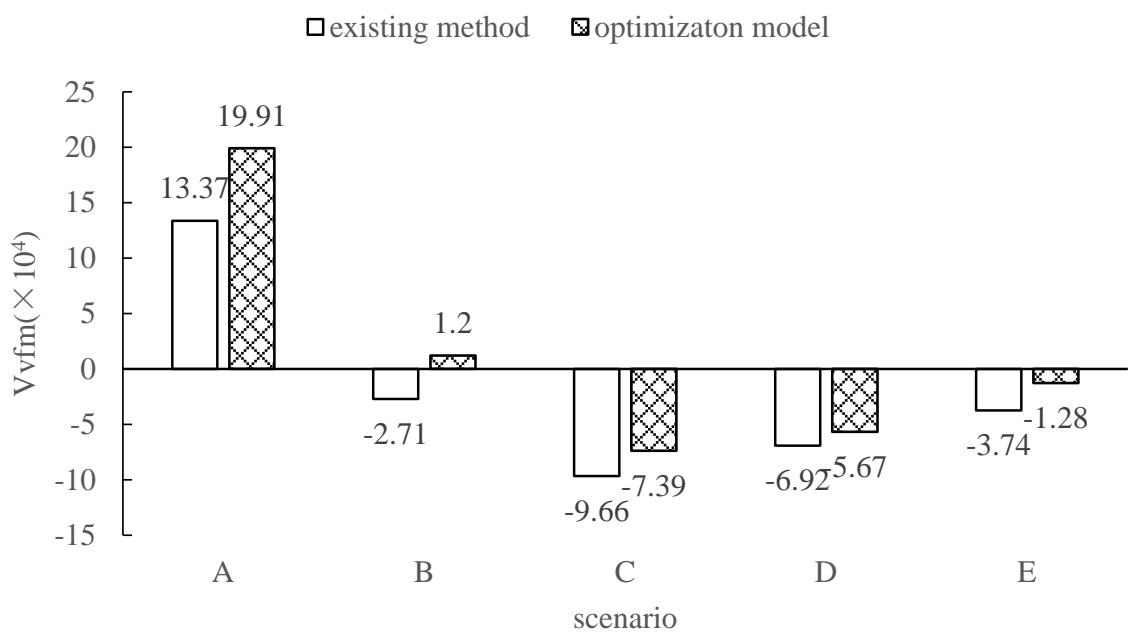

Fig. 3. Comparison of maximum VFM values separately conducted via optimized method and existing method

Figure 4 shows the comparison of $Y_{\max }$ value between the existing method and the optimization model. $Y_{\max }^{*}$ is the maximum value $Y$ could reach under the constrains of all project resources and payback expected by the private sector. According to the principle of the optimization method depicted in Figure 2, this VFM value ( $Y_{\max }^{*}$ ) could be used as an effective reference for determining the two issues in Introduction part. The existing method draws a conclusion that there is no acceptable strategy under scenario B, C, D and E, which reflects existing method is not always effective for the 1-st issue that 'is there any acceptable strategy in project'. Besides, the maximum VFM value generated by existing method under scenario A is much smaller than that generated by optimization model, which reflect existing method is less efficient than the optimization model.

Table 5. Effectiveness of the nonlinear programing model

\begin{tabular}{ccccccccc}
\hline \multirow{2}{*}{ scenario } & $Y_{\max }^{*}$ & $U^{*}$ & $X_{1}^{*}$ & $X_{2}^{*}$ & $X_{3}^{*}$ & $X_{4}^{*}$ & effective times in 10000 & effectiveness \\
\hline A & 19.91 & 0 & 0.49 & 22.36 & 0.57 & 30 & 8188 & $81.88 \%$ \\
B & 1.2 & 0 & 0.49 & 27.82 & 0.57 & 30 & 8329 & $83.29 \%$ \\
C & -7.39 & 0 & $\underline{0.2}$ & 44.45 & 0.57 & 30 & 8369 & $83.69 \%$ \\
D & -5.67 & 0 & 0.49 & 35.87 & $\underline{0.33}$ & 30 & 7627 & $76.27 \%$ \\
E & -1.28 & 0 & 0.49 & 30.88 & 0.57 & $\underline{26.6}$ & 9451 & $94.51 \%$ \\
\hline
\end{tabular}

(the underlined value means it keeps constant in calculation) 
Subject to limitation of the solver fmincon() on Matlab 9.1.0.441655 (R2016b) that affected by initial input value of variables, $Y_{\max }^{*}$ in Table 4 could not be obtained in every trial. Thus, strategy with $Y_{\max }^{*}$ is considered as effective and strategy with $Y<Y_{\max }^{*}$ is considered as non-effective. The last column in Table 5 shows the effectiveness of the optimization model.

In summary, the existing method might not be effective and efficient in two issues proposed in Introduction part, while the optimization model could provide comparatively accurate results. Nevertheless, the optimization model could not always provide the non-inferior solution. The minimum effectiveness of the model for one-time evaluation under 5 difference scenarios is above 76\%. Results of scenarios C, D and E shows that it is hard for URT project to obtain an acceptable strategy without commercial develop benefit as the supplementary fund flow to the private sector. Such situation becomes severe then lead to project cannot achieve 'Value for Money' when the public sector chooses the equity ratio upon the minimum level of capital fund, charge user at the average level of ticket fare or set the operation period shorter than that of average length of other URT projects.

\section{Conclusion}

At current stage, decision-makers from the public sector is more concerned with issues that 'any acceptable strategy exists within the project' and 'the maximum VFM value lies in acceptable strategies' than whether a single strategy is acceptable. To this end, an emerging evaluation method is proposed in this paper established upon non-linear programing model based on the idea 'evaluate after optimized'. Theoretically, the model could directly provide an optimal solution within limited project resources and on condition that payback of the private sector is satisfied. The optimization model is compared with the existing method via 10000 independently repeated trials using data of a sample case. Results showed that the existing method might not be effective and efficient in solving the two issues while the optimization model got an accuracy above $76 \%$ in one-time evaluation.

Follow-up research can be carried out from these:

The operation revenue and cost are simplified as the basic function of time variable, but which could present complex fluctuation in practice. Distribution of parameters value along with time change needs to be mined deeply to improve the accuracy of the optimization model.

The commercial development option fills the gap between low revenue and high cost in a usual PPP project. How such option would impact on URT PPP project strategy would is worth to explore.

\section{References}

[1] Ke, Y.; Hao, W.; Ding, H.; Wang, Y. Factors influencing the private involvement in urban rail public-private partnership projects in China. Construction Economics and Building 2017, 17, 90-106.

[2] Zhang, S.; Gao, Y.; Feng, Z.; Sun, W. PPP application in infrastructure development in China: Institutional analysis and implications. International Journal of Project Management 2015, 33, 497-509..

[3] Osei-Kyei, R.; Chan, A.P. Review of studies on the Critical Success Factors for Public-Private Partnership (PPP) projects from 1990 to 2013. International Journal of Project Management 2015, 33, 1335-1346.

[4] Hou, S. in Value-for-Money assessment in China's public-private-parternship project present situation, problems and policy suggestions, Industrial Economics System and Industrial Security Engineering (IEIS'2017), 2017 4th International Conference on, 2017; IEEE: 2017; pp 1-4.

[5] Zhang X R. Quantitative Assessment on Value for Money for Urban Rail Transit PPP Projects [D]: Beijing Jiaotong University, 2016.

[6] Tang L. Application Study on Quantitative Evaluation of VFM in Toll Free Highway [D]: Southwest Jiaotong University, 2017. 
[7] Luo Y Y. The Quantitatively Evaluated Study of Value for Money in Sewage Treatment Plant's PPP Project [D]: Southwest Jiaotong University, 2017.

[8] Zhao Y D. PPP Cooperation Mode of Government and State-owned Enterprises in Transportation Infrastructure Projects Construction [D]: Chang'an University, 2016.

[9] Wang Y Y, Ke F, YIinJ, et al. The Construction and Application of VFM Evaluation Model Taking Urban Rail Transit PPP Project as Example. [J]. Project Management Technology. 2015,13(08):21-27.

[10]China Public-Private-Partnerships Center (СPPPC), Project information database, http://www.cpppc.org:8083/efmisweb/ppp/projectLibrary/toPPPList.do 